\title{
Hand Interosseous Muscle
}

National Cancer Institute

\section{Source}

National Cancer Institute. Hand Interosseous Muscle. NCI Thesaurus. Code C53173.

Two sets of interossei muscles (dorsal and palmar) that run along the metacarpal bones

in the hand controlling the movement of the fingers. 